Acta Universitatis Wratislaviensis No 4087

Anglica Wratislaviensia LIX, Wrocław 2021

https://doi.org/10.19195/0301-7966.59.1

\author{
Mariusz Marszalski \\ ORCID: 0000-0003-4027-5589 \\ Universty of Wrocław \\ mariusz.marszalski@uwr.edu.pl
}

\title{
Speculations on the Future of Economic Models in the Wake of Trans/Posthuman Sentient Evolution in Charles Stross's SF Novel Accelerando
}

\begin{abstract}
Economy, understood as a domain of production, distribution and consumption of goods and services, has been unquestionably comprehended as a social activity, the purpose of which is to satisfy first of all vital material, but also immaterial, needs of the biological natural human being. Whatever the underlying ideology — whether protectionist mercantilism, the physiocrats' laissezfaire policy, Adam Smith's free-market capitalism, Karl Marx's socialist economics, Keynesian state interventionism, or present day neoliberalism - economic considerations have been invariably driven by the fundamental problem of scarcity. The objective of the proposed paper is to present Charles Stross's speculative predictions, made in his SF novel Accelerando, about the future of economic models in light of trans/posthuman evolution hailed by, among others, Ray Kurzweil, Max More, and Hans Moravec.
\end{abstract}

Keywords: speculative fiction, transhumanism, posthumanism, economy, sentient evolution

Economy, understood as a domain of production, distribution and consumption of goods and services, has been unquestionably comprehended as a social activity, the purpose of which is to satisfy first of all the vital material, but also immaterial, needs of the biological natural human being. Whatever the underlying ideologywhether protectionist mercantilism, the physiocrats' laissez-faire policy, Adam Smith's free-market capitalism, Karl Marx's socialist economics, Keynesian state interventionism, or present day neoliberalism - economic considerations have been invariably driven by the fundamental problem of scarcity. The objective of the proposed paper is to present Charles Stross's speculative predictions about the future of economic models in light of the trans/posthuman evolution hailed by, among others, Ray Kurzweil, Max More, and Hans Moravec. 
Stross embarks on an ontological speculation about who may participate in the economic processes of future societies and under what conditions. So far, the agents of the economy have been individual persons, as well as companies and institutions run by human managers. However, the novelist conjectures, what if singularity meant that a rise of self-conscious Artificial Intelligence takes place? What if economic units emerge controlled and managed by software bots, whose level of sentience will entitle them to property ownership? Considering the ever-accelerating technological progress, will scarcity still dominate economic thinking? Will it be an issue for potential mind-uploading people living in realms of virtual reality? Addressing such questions, Stross depicts a visionary posthuman future in which the economy as we know it comes to an end, only to be replaced by varieties of post-economies, such as the post-scarcity economy, allegedly possible due to advanced automated manufacture of goods; the post-capitalist economy, no longer based on markets and private ownership; and the open-access economy, free from money, trade or governance limitations.

While hypothesizing about a remote, trans/posthuman future of the world's economic systems, it seems justified to preliminarily disregard two of them: the tradition-based model and the centrally-organized command system. The former is historically the oldest, but its occurrences as the prevailing system are rare nowadays. Its economic arrangements, consisting of supplying subsistence foods by means of hunting and gathering and providing everyday necessities, including shelter, clothes, and tools, go back to prehistoric Paleolithic groups of Neanderthals and the Cro-Magnon modern humans. For thousands of years, tradition-based primitive societies have maintained this changeless socio-economic mode of life, performing the basic tasks of production and distribution according to time-sanctioned patterns resulting from timeless perpetuation of the few existing social roles. Even today, in the space age, there are some communities of the Inuit, Kalahari hunters and Bedouin semi-nomads who still preserve a few forms of tradition-based economy (Boettke, Heilbroner). And since conservative ways of life die hard, it may be prognosticated that this kind of economic arrangements will continue, though increasingly marginally, into an indeterminate future in inhospitable geographical regions, like deep deserts or the Arctic and the Antarctic Circles.

Command systems are relatively irrelevant to the present discussion, too. Though very old in origin, they have not undergone essential functional changes. They have persisted since ancient times, when powerful centralized civilizations emerged in China, India and Egypt in the $3^{\text {rd }}$ millennium BC. As they "utilize the open or veiled power of physical coercion or punishment, or the bestowal of wealth or prerogatives", they are capable of mobilizing "resources and labour in ways far beyond the reach of traditional societies" (Boettke, Heilbroner). Accordingly, societies organized according to "the command systems typically boast of large-scale achievements such as the Great Wall of China [,] the Egyptian pyramids" or "the vast temple complexes, irrigation systems, fortifications, and cities of ... the king- 
doms of the Inca and Maya" (Boettke, Heilbroner). Typical of former great historic empires, since the $20^{\text {th }}$ century, command systems have been largely associated with different forms of communism, socialism and dictatorship. Projecting their existence into the future, we can presume that since authoritarian governments are not new to humanity, in the future, when they appear, they will keep making use of command as their coordination system, with one important proviso: that they are able to control both human and technological resources.

Charles Stross's Accelerando (2005), being a futuristic SF novel, bypasses the aforementioned older economic models only to speculate on the future of historically the youngest, but currently globally-widespread capitalist system and its post-capitalist developments. Carrying out his thought experiment, the writer joins a select group of authors dealing with economic issues in speculative fiction. As an example, visions of post-scarcity societies are featured in Kim Stanley Robinson's The Mars Trilogy (1993-1996), Neal Stephenson's cyberpunk novel The Diamond Age (1995), Cory Doctorow's Down and Out in the Magic Kingdom (2003), and Iain M. Banks' The Culture novels series (1987-2012). In turn, predictions about the future of business and labor markets, including such problems as demise of corporations, emergence of cooperative and gig economies, and obsolescence of human work force can be found in Vernor Vinge's Rainbows End (2006) or Cory Doctorow's novels Makers (2009) and Walkaway (April 2017). What makes Charles Stross's Accelerando remarkable, when viewed against the aforementioned works, is the extent to which it deals with imaginary post-singularity economies that involve not only human subjects, but also humanity's evolutionary post-human and Artificial Intelligence offspring.

The baseline reality serving as a point of departure for Stross's venture into the imaginary post-human future is the early twenty-first century. The world's most prevalent form of economy rests on the free-market underpinnings and may be identified as the third, late phase of capitalism, as depicted by Marxist economist Ernest Mandel in his seminal book Late Capitalism (1972). Its advanced characteristics, comprising globalism, multinational corporations, mass communication, new digital media, consumerism, and international finance, call to mind Alvin Toffler's Third Wave Society, with its intertwined techno-info sphere and accelerative economy (Toffler 193-194, 246), as well as Fredric Jameson's view of late capitalism, featuring:

new international division of labor, a vertiginous new dynamic in international banking and the stock exchanges ... new forms of media interrelationship, ... computers and automation, the flight of production to advanced Third World areas, along with all the more familiar social consequences, including the crisis of traditional labor. (xix)

However, since Stross takes his readers into a speculative future, he chooses to start his story against the background of a prolonged systemic crisis of the world capitalist economy that seems to be heading toward a turning point beyond which capitalism as we know it will be replaced by a new, perhaps mixed-economy paradigm. 
One of the options for overcoming the malady of the profit-driven market economy that Stross takes into consideration is to try to jump the hurdle of the historical "central planning" communist and socialist economies' struggling "to interface a central planning system with a capitalist economy" (Accelerando 59). ${ }^{1}$ Doing a pilot project with the Italian Communist Party in mind, the main character, Manfred Macx, a geek inventor and entrepreneur, acts on an impulse to cock a snook at the Chicago School of neo-classical economics. He comes up with an idea how to improve a command economy that must by its nature be coercive. To eliminate the imperfections of the human factor, he delegates the command functions to digital computational systems that handle the classic central planning system resource-allocation problem "Using a network of interlocking unmanned companies" (Accelerando 51). Substituting for wasteful market mechanisms, he devises "a state central planning apparatus that interfaces perfectly with external market systems" (Accelerando 58), which, if implemented, could algorithmically outperform any free-market economy.

However, considering a vast variety of political ideologies and their concomitant economic systems, Manfred's digital technology-aided efficient central planning arrangement is more of a thought exercise than a viable alternative to the global market economies of his day. Being a visionary genius, he leaves it behind, thinking ahead into the post-scarcity future that is inexorably approaching, though apparently still few people are aware of the change. The economic behavior that he practices and indorses, much to the ire of the conventional state agencies, such as the American Internal Revenue Service, is the idea of agalmics put forward by Robert Levin in his essay "The Marginalization of Scarcity".

While any kind of economics known up to this date has been concerned with the allocation of scarce resources and goods, agalmics, as defined by Robert Levin, is "[t]he study and practice of the production and allocation of non-scarce goods." As "technological change continues to occur", Levin assumes, "over time, more and more basic goods will become less and less scarce", like for instance free software. Unlike the conventional market economics, often described as a zero-sum game, "Efficient agalmics is a positive-sum game. For example, when a free software programmer gives his source code away, he gains a large population of users to report bugs; the users gain the use of his programs." Instead of monetary profit, "agalmic profit is measured in such things as knowledge, satisfaction, recognition and often in indirect economic benefit".

Charles Stross's main character thinks along these lines. He deems that humanity is heading toward the economic singularity, understood as a moment in time-as described by William Nordhaus in his paper "Are We Approaching an

${ }^{1}$ In the last few decades, the Republic of China has succeeded in developing an effective model of state capitalism. As Richard D. Wolff describes it, "Chinese state capitalism is a hierarchy with the party and government at the top, state and private employers below them, and the mass of employees comprising the bottom". 
Economic Singularity?" - when "rapid growth in computation and Artificial Intelligence will cross some boundary or Singularity after which economic growth will accelerate sharply". Developing exponentially, Artificial Intelligence will "have the potential to increase its productivity and breadth to the extent that human labor and intelligence will become increasingly superfluous". Actually, Manfred's, and thus Stross's, prognostications are more futuristic than those of the 2014 OECD economic policy paper on "Policy Challenges for the Next 50 Years", but generally, they concur with them on such issues as the knowledge-based growth, the changing structure of labor and the necessity to ameliorate rising social inequalities. With an eye to the post-scarcity future, "Manfred doesn't believe in scarcity or zero-sum games or competition - his world is too fast and information-dense to accommodate primate hierarchy games" (Accelerando 41). When he fights the music cartels to set recorded music free, giving it back to the public domain, or when he patents his ideas, always signing the rights over to the Free Intellect Foundation, he fosters a new economics that he anticipates. As he says, contesting his "born-again, post-conservative" (Accelerando 42) wife Pam, "I work for the betterment of everybody, not just some narrowly defined national interest ... It's the agalmic future. You're still locked into a pre-singularity economic model that thinks in terms of scarcity. Resource allocation isn't a problem anymore-it's going to be over within a decade" (Accelerando 20).

The above considerations, being set in the pre-singularity, human epoch, pertain to human scale economics, termed in the novel as Economics 1.0. A perennial problem of this kind of economics has been its grappling to meet the needs of the ever-growing world population. In his 1798 essay "Principle of Population", Thomas Malthus expressed his concern, writing, "Assuming then my postulata as granted, I say, that the power of population is indefinitely greater than the power in the earth to produce subsistence for man. Population, when unchecked, increases in a geometrical ratio. Subsistence increases only in an arithmetical ratio" (4). While this rule might be still binding in the industrial era, Stross envisions that in the post-industrial, information one, it will no longer be valid. Actually, in the universe he imagines, the post-singularity economic growth outstrips the expansive human demographic increase immeasurably.

The demographic dynamics and developments of the human race can be speculatively traced forward in the sort of State of Humanity reports appearing recurrently in the novel. Beginning with "Welcome to the early twenty-first century" (Accelerando 38), through "Welcome to the eve of the third decade" (Accelerando 75), or "Welcome to the fourth decade" (Accelerando 117), we can follow probable world population trends. And thus, readers learn that the birthrate declines across Europe despite the EU subsidizing babies (Accelerando 49), then population growth throughout the developing world stalls, with the birthrate dropping below replacement level (Accelerando 75), and still further on in time, "The human population is near maximum overshoot, pushing nine billion, but its growth rate is tipping to- 
ward negative numbers" (Accelerando 117). Nine billion people is still a vast number, but a global economy predicated on high technology, involving nascent AIs, is immensely efficient. Bangladesh, symbolic of dire poverty just a few decades ago, enjoys an economic miracle. As the narrator says:

cheap out-of-control bio-industrialization has swept the nation: Former rice farmers harvest plastics and milk cows for silk ... With cellphone ownership nearing eighty percent and literacy at ninety, the once-poor country is finally breaking out of its historical infrastructure trap and beginning to develop: In another generation, they'll be richer than Japan. (Accelerando 147)

Playing with the prospects of the world's economy, Stross goes beyond the possibility of its progress being achieved by standard humans who develop new cutting-edge technologies that increase work productivity. Actually, he ventures further into a futuristic posthuman future that involves a transformation of human-only societies into ones that would accommodate products of posthuman evolution, including augmented humans and transformed posthumans, as well as Artificial Intelligence life forms that would be granted civil rights as sentient and sapient offshoots of human wetware-based intelligence. Imagining a posthuman reality with its emergent economies, the writer draws a picture that coincides with some key predictions about the coming of the Singularity by such leading futurist thinkers as Vernor Vinge, Ray Kurzweil and Nick Bostrom.

The idea of the Singularity associated with the creation of technological superintelligence is a constitutive thread of the novel's plot. Using Vinge's wording from his influential essay "Technological Singularity", the paradigm shift that jolts the human world in Accelerando amounts to "a throwing-away of all the human rules... an exponential runaway beyond any hope of control", which marks an epochal change that affects the humans' role in the order of things, including its economic underpinnings. As history reaches the eighth decade of the third millennium, the narrator reports, the Earth's

eleven billion future-shocked primates ... are just barely intelligent tool users; Darwinian evolutionary selection stopped ... Now the brightly burning beacon of sapience isn't held by humans anymore - their cross-infectious enthusiasms have spread to a myriad of other hosts, several types of which are qualitatively better at thinking. (Accelerando 266)

Humanity is inevitably past the event horizon of the economic singularity. As we learn, "The last great trans-global trade empire, run from the $\operatorname{arcologies}^{2}$ of Hong Kong, has collapsed along with capitalism, rendered obsolete by a bunch of superior deterministic resource allocation algorithms collectively known as Economics 2.0" (Accelerando 266).

Stross's Accelerando is a dystopian take on the future of human economic practices. His Economics 2.0 and its prospective higher releases result from the

2 The concept of arcology was introduced by architect Paolo Soleri in his book Arcology: City in the Image of Man in 1969. The idea involved a fusion between architecture and ecology. 
Singularity that initiates a new reality combining, on a higher level of complexity, self-organizing AIs and posthumans merged with nanotechnology that, in Ray Kurzweil's vision, "will enable our human-machine civilization to transcend the human brain's limitations of a mere hundred trillion extremely slow connections" (20). The new economics outperforms any system known before. Energy and computational power are no longer scarce resources, as matter in the solar system is being dismantled and gradually transformed into semi-intelligent computronium. ${ }^{3}$ The entire mass of the solar system turns into "a free-flying shell of nanocomputers, then more of them, Dyson spheres, ${ }^{4}$ shells within shells, like a Russian doll: a Matrioshka brain"5 (Accelerando 323). On top of that, business interactions among the agents of the economy are abstractly well optimized and efficient, which allows these societies to achieve fabulous wealth. However, from the traditionally human point of view, embracing the post-singularity economics is suicidal, for participation in it requires entering on a path of artificial evolution that, as Bostrom warns in his essay "The Future of Human Evolution", might leave "no niche for mental architectures of a human kind" (4).

Stross concurs entirely. Within an ever-accelerating economy, human skills tend to become obsolete at an exponential rate. In capitalism, you might try to retrain, but being an unaugmented human, Sirhan, Manfred's grandson says, "You can't retrain as a seagull, can you, and it's quite as hard to retool for Economics 2.0" (Accelerando 308). Still, technological unemployment is not the worst thing. At the beginning, seeking to maximize computational fitness, some people decided to upload. To speed up their performance, they could copy themselves, but "they were still human, and unable to operate effectively outside human constraints" (Accelerando 307, emphasis original). This has changed irrevocably, though. "Take a human being and bolt on extensions that let them take full advantage of Economics 2.0", Shiran explains, "and you essentially break their narrative chain of consciousness, replacing it with a journal file of bid/request transactions between various agents; it's incredibly efficient and flexible, but it isn't a conscious human being in any recognizable sense of the word" (Accelerando 307).

In conclusion to the foregoing reflections on the possible future of human economic systems, the question arises if human-oriented economies in the aftermath of the singularity prophesied by futurists should be all about wealth production and

3 The idea of computronium - "programmable matter" - was developed by Norman Margolus and Tommaso Toffoli of the Massachusetts Institute of Technology and published in their 1987 paper "Cellular Automata Machines".

4 "A Dyson sphere", Adam Mann explains, "is a theoretical mega-engineering project that encircles a star with platforms orbiting in tight formation". The idea was popularized by Freeman Dyson in his 1960 paper "Search for Artificial Stellar Sources of Infrared Radiation".

5 A Matrioshka Brain "is basically a giant computer that uses the entire energy output of a star... Technically, at least the inner shell of a Matrioshka Brain is a Dyson Sphere, which is defined as a structure that completely encompasses a star and captures a large percentage of the star's energy output" (de Haan). 
about cost and profit efficiency. Interrogating this query, we have to remember that the goal of any form of human economics is to meet the demand for the goods and services people need, while realizing at the same time the more general truth that our needs go beyond mere physical subsistence. Posthumans, aiming at maximizing fitness, might not resent becoming all-work-and-no-fun demi-gods, but we oldtype humans are different. As Nick Bostrom aptly remarks, ours is a eudemonic, pleasure-seeking nature, for "Much of human life's meaning arguably depends on the enjoyment, for its own sake, of humor, love, game-playing, art, sex, dancing, social conversation, philosophy, literature, scientific discovery, food and drink, friendship, parenting, and sport" (6). It is these features acquired in the course of our Darwinian evolution that make us human. Artificial evolution, with its new economic developments, might admittedly make future posthumanity rich beyond imagination, but the ever-dwindling minority of human old-timers would be outcompeted by more effective life forms. The process, Bostrom posits, would "lead to the gradual elimination of all forms of being that we care about" (1, emphasis original), the prediction being fittingly endorsed by Stross's statement in the novel that "true participation in Economics 2.0 is not possible without dehumanizing cognitive surgery" (Accelerando 334).

At the end of the book, Stross offers a resolution of the quandary signaled above, suggesting that perhaps in order to salvage what we consider human in us, it would be wise to keep away from participating in Economics 2.0, even while taking advantage of some of its advanced mind-body enhancements. Stross and Bostrom apparently coincide on this issue, for Accelerando ends with less than posthuman people coalescing around the idea of bringing into being a society not unlike Bostrom's singleton, defined as "a world order in which at the highest level of organization there is only one independent decision-making power (which may be, but need not be, a world government)" (3). The Saturn-orbiting, continent-size terraformed colony is a refuge for humans seeking shelter from overwhelming post-singularity changes. Eudemonic types and activities are promoted and well provided for. Though incomparably poorer than Economics 2.0 societies, this one is not a scarcity one. As newcomers are informed, money still exists and "is used for the usual range of goods and services, but the basics - food, water, air, power, off-the-shelf clothing, housing, historical entertainment ... are free" (Accelerando 334, emphasis original). Envisioning a future of humanity driven by an uncontrolled self-evolution impetus, Stross seems to caution us against its excesses. Were a post-singularity scenario to come true, scarcity might not be a problem, but the days of the human species as we know it might be numbered. Engulfed by higher order economics, the unadapted ones would face an alternative of either becoming upgraded or suffering a functional degradation, leading to their gradual marginalization and displacement. To forestall such a possibility, the residents of Saturn are warned of "entering into financial contracts with entities running Economics 2.0 or higher" on par with "giving your bank account details to the son of the Niger- 
ian Minister of Finance; buying title to bridges, skyscrapers, spacecraft, planets, or other real assets" (Accelerando 335). The warning may sound hilarious, but it is meaningful nevertheless. The truth is that few people can say sincerely that they understand the working of their contemporary economic systems. In a future run by AIs and posthumans, we would hardly be able to keep up with fast accelerating changes rendering older systems obsolete at an ever-shorter notice, unless we had positronic brains, but then it would be quite a different story of an alien race.

\section{References}

Boettke, P. J. and R. L. Heilbroner. "Economic systems.” Encyclopaedia Britannica. Retrieved from https://www.britannica.com/topic/economic-system. 3 May 2020.

Bostrom, N. 2004. "The Future of Human Evolution." Retrieved from https://www.nickbostrom. com/fut/evolution.pdf. 4 May 2020.

De Haan, H. 2019. “Matrioshka Brain: The Ultimate Intelligence.” Data Driven Investor. Retrieved from https://medium.com/datadriveninvestor/matrioshka-brain-the-ultimate-intelligence-5d6 2fa31208f. 15 September 2020.

Jameson, F. 1991. Postmodernism or the Cultural Logic of Late Capitalism. Durham: Duke University Press.

Kurzweil, R. 2005. The Singularity is Near: When Humans Transcend Biology. NY: Penguin Books.

Levin, R. 1999. "The Marginalization of Scarcity.” Retrieved from http://project.waag.org/browser/ browserday_1999/reader/themarg.html. 23 July 2020.

Malthus, T. 1798. "An Essay on the Principle of Population." London: Printed for J. Johnson, in St. Paul's Church-Yard.

Mandel, E. 1978. Late Capitalism. Transl. Joris De Pres. London: NLB (Verso Edition).

Mann, A. 2019. "What Is a Dyson Sphere?" Space.Com. Retrieved from https://www.space.com/ dyson-sphere.html. 10 August 2020.

Nordhaus, W.D. 2017. "Are We Approaching an Economic Singularity? Information Technology and the Future of Economic Growth." Retrieved from https://www.nber.org/system/files/working_papers/w21547/w21547.pdf. 12 July 2020.

"Policy Challenges for the Next 50 Years." (2014). OECD Economic Policy Papers, No. 9. Retrieved from https://www.oecd.org/economy/Policy-challenges-for-the-next-fifty-years.pdf. 4 May 2020.

Stross, C. 2006. Accelerando. New York: Ace Books.

Toffler, A. 1980. The Third Wave. New York: Morrow.

Vinge, V. 1993. "Technological Singularity.” Retrieved from https://frc.ri.cmu.edu/ hpm/book98/ com.ch1/vinge.singularity.html. 3 August 2020.

Wolff, R. D. 2020. "Socialist or capitalist: What is China's model, exactly?" Brave New Europe. Politics and Economics: Expertise with a Radical Face. Retrieved from https://braveneweurope. com/richard-d-wolff-socialist-or-capitalist-what-is-chinas-model-exactly. 30 August 2020. 
Anglica Wratislaviensia LIX, 2021

(C) for this edition by CNS 